\title{
PATIENT SAFETY - CONCEPT AND CHARACTERISTICS OF SAFETY. THE HUMAN FACTOR IMPACT
}

\author{
Anna Kircheva ${ }^{1}$, Rumen Konstantinov ${ }^{2}$ \\ ${ }^{1}$ Department of Clinical Medical Sciences, Faculty of Dental Medicine, \\ Medical University of Varna \\ ${ }^{2}$ Department of Hygiene, Disaster Medicine and Epidemiology, Faculty of Public Health, \\ Medical University of Varna
}

\begin{abstract}
INTRODUCTION: We have learned over the past 15 years that patients can be harmed by many factors in the healthcare system or factors associated with healthcare providers. Healthcare emerges as one of the most unsafe industries. Studies show that in the developed countries approximately $10 \%$ of the hospitalized patients suffer an adverse event or incident. The global survey of unexpected harm conducted by WHO and the World Alliance for Patient Safety indicates that the most frequent incidents result from: healthcare-associated infection (HCAI), medication errors, unsafe surgery, clinical handovers, injection safety.

AIM: The aim of this study is to do a systematic review on the existing practices and solutions applied in the period 2001 - 2016 with regard to patient safety. The issue has been systematically analyzed based on published results from the research work of WHO teams and leading authors on the subject.

RESULTS AND CONCLUSION: All applied programs of WHO concerning patient safety aim to coordinate actions, disseminate knowledge and accelerate improvements in patient safety worldwide. Patient safety is an issue that impacts all countries and all governments who provide health services.
\end{abstract}

Keywords: patient safety, adverse event, reviews, healthcare

\section{INTRODUCTION}

Sufficient evidence from various fields of medicine has been gathered in the recent 15 years, showing how a patient can be harmed after he had sought aid from the healthcare system or healthcare providers. The developed medical science and technologies place medical aid in a system, which is both intricate and hard to manage. This system, in its turn, continuously generates risks of adverse events for the patients, regardless of the degree of specialization and

Address for correspondence:

Anna Kircheva

Medical University of Varna

55 Marin Drinov St

9002 Varna, Bulgaria

e-mail:kircheva@svetaanna-varna.com training of the healthcare providers. The sensitivity of the topic of safety where human health is concerned finds expression in the leading operational principle "Do no harm," adopted by the World Alliance for Patient Safety - 2004 (1). The controlled epidemiological research on the adverse events related to healthcare conducted by experts from the World Health Organization (WHO) and the World Alliance for Patient Safety report an unusually high rate of harm: 8 - 15\% of the hospitalized patients $(2,3)$. Evidently, healthcare turns out to be one of the most dangerous industries in the human society. The adverse events (AE) reported predominantly by economically developed countries after 2000 show that: 
Anna Kircheva, Rumen Konstantinov

$\diamond$ The clinical result is related to an adverse event in approx. $15 \%$ of the hospitalized patients, Australia, 2007.

$\diamond$ One of every 10 hospitalized patients in the economically developed countries suffers disability in result of error or for another reason.

$\diamond$ Out of 100 hospitalized patients, one develops a healthcare-associated infection (HCAI).

$\diamond$ The dangerous injection practices account for $33 \%$ of the new cases of viral hepatitis B, $42 \%$ of viral hepatitis $\mathrm{C}$ and $2 \%$ of the HIV infections worldwide.

$\diamond$ For 234 million surgical interventions annually performed worldwide, 7 million cases of infection-related complications or errors have been reported and 1 million patients have died.

$\diamond 20-40 \%$ of the funds spent for healthcare worldwide have been incorrectly directed or inadequately used $(1,4,5,6,7,8,9)$.

Patient safety is the cornerstone of high quality in healthcare. That is why the debate about quality healthcare of the recent years is an important aspect of the safety topic. The essence of quality is typically sought in the optimum balance of different possibilities put into operation within a certain framework of norms and values. They determine the rules in human communication and assure quality. Consequently, the social element is crucial for this philosophic and life category. The impact of quality on healthcare affects the individuals and the community in equal measure (6).

\section{Concept and Characteristics of Safety}

Currently, the expert opinion defines patient safety in the following way: The reduction of risk of unnecessary harm associated with healthcare to an acceptable minimum, (WHO-ICPS,2009). The concept of adverse event (AE) is: An incident in which a patient is harmed $(2,4,6)$.

Safe medicine emerges as a generally new direction in medicine, the aim of which is to safeguard the patient against unnecessary or potential harm that might result from provided healthcare (WHO, 2005). Harm is associated with negative results that damage the human health and have occurred as a result of provided healthcare (1).

The evidence for adverse events and potential risk practices associated with patient safety have been identified on the grounds of reports and controlled clinical and systematic research, and expert consultancy. The obtained results focus the issue mainly on hospitalized patients. The end result is assessed on the grounds of the clinical end point - morbidity and death rate, and the hazardous practices are defined through consensus and classification made on the strength of collected evidence $(10,11,12,13,14)$. The researched practices providing the strongest evidence for risk of adverse event refer to:

1. medicinal prevention of venous tromboembolism;

2. perisurgical application of beta-blockers;

3. aseptic at central venous catheterization;

4. antibiotic prevention at surgical patients;

5. omissions in the patient's informed consent;

6. prevention at ventilator-associated pneumonia;

7. prevention of bedsores;

8. supersonic and/or X-ray control in the performance of invasive procedures;

9. conducting of anticoagulation therapy;

10. enteral/parenteral nutrition of surgical patients and patients in critical condition;

11. use of venous catheters for infusion therapy.

The Conceptual Framework for Patient Safety used for the classification of patient safety puts the focus on the crucial risk factor that is responsible for the clinical incident. At its interpretation, special attention is paid to the timely detection of the potential risk and the applying of suitable prevention tools $(5,15,16)$. Preventable harm is mainly a clinical issue but it is also a signal for invested and inadequately used health resources.

The National Forum on Quality organized in Washington, USA in 2006, tried to bring clarity on the subject; towards this aim, it developed taxonomy for patient safety and defined its frame. In this way, harm and its consequences can be defined for the most frequent and definitively proven incidents that occur in the course of patient treatment $(5,6,15,16)$. Two different approaches are used for the classification of issues:

1. Identified patient harm occurred as a result of: error; unsuccessful communication with the patient or medical team; treatment - improper, 
Patient Safety - Concept and Characteristics of Safety. The Human Factor Impact

systematically unmonitored, and inadequately used resources.

2. Additional classification of errors according to the type and pathway of provided healthcare:

2.1. wrong solutions, which influence the procedures and the distribution of resources (internal organization of healthcare);

2.2. insufficient activity or direct contact with the patient;

2.3. organizational weaknesses and management;

2.4. technical weaknesses - equipment failures, unavailable resource for failure correction or equipment replacement.

Clearly, some of these issues are universal and concern activities related to the organization of healthcare. Other issues are selective and find demonstration in zones of higher risk for the patient. The latter require specific approach, which Wandelt sees in the creating of consensus standards $(7,17,18)$.

Cases of dangerous healthcare are continuously reported by countries of varying degrees of economic development and, apart from the medics, these cases become the concern of politicians, researchers and specialists working in many different areas. This is an issue affecting all countries worldwide. It calls for action, best expressed in the message promoted by the World Health Organization: "Each patient to receive safe care, every time and everywhere." (19).

Patient safety is the stepping stone towards better healthcare on a global scale. The World Health Organization is a unifying and guiding unit that organizes and directs the processes, sets the necessary norms and standards, and seeks public support in the provision of safe healthcare policy. Currently, over 800 research, academic and hospital structures and public organizations from across 80 member states have joined efforts towards the successful implementation of a number of researches and program initiatives conducted worldwide. In the recent ten years, the World Alliance for Patient Safety (2002) has implemented successfully a number of international programs in the medical practice: in the area of surgery - Safe Surgery and Surgical Safety Checklist; safe childbirth - Safe Childbirth and Checklist; safe blood transfusion and injection practices Global Collaboration for Blood Safety and Injection
Safety; HCAI prevention - Clean Care is Safer Care; directly related to antibiotic resistance - Campaign to Prevent Antimicrobial Resistance $(20,21,22,23,24,25$, $26,27,28,29)$. The implementation of these practices provided an opportunity for the experts working in the various fields of medicine to develop new standards for medical activities - checklists, and to introduce evidence-based policies of significant effect on patient safety in key healthcare areas.

\section{The Human Factor and Patient Safety}

The experience accumulated through the years helped highlight the leading role of the human factor amongst the cluster of components bearing impact on healthcare. This is a two-direction impact. On the one hand there is a human being - as a subject and recipient of healthcare, i.e. he is the patient; on the other hand there is a human being as a donor or operator, i.e. he is the medical staff engaged in the healthcare provided to the patient. The research of and the familiarization with the human factor is an important prerequisite towards limiting the negative effect of adverse events in healthcare provision. If human weaknesses and strengths are not taken into consideration in the process of planning of medical activities, such activities can turn out to be difficult and confusing for implementation. Alternatively, they can be made safe and effective (2). Typically, the human brain reacts quickly to changes in the environment; it filters the information and finds alternative methods and solutions. Unlike the new technical means that have been implemented in the medical practice, man remains unpredictable, is easily distracted and his abilities to process large volumes of information remain limited. The safe work with the patient is often defined by certain situations that increase the risk of error, such as: not knowing one's assignments; inexperience; shortage of time; poorly designed procedures; poor equipment; poor humanequipment interface; limited memory capacity because of fatigue, stress, malnutrition, illness, etc. It is considered that sleep deprivation of 24 hours has a performance effect equivalent to blood alcohol content of $0.1 \%(30,31,32)$.

The provision of safe working environment offers an opportunity for an easy adaptation of the human factor and for the performance of simplified and standardized procedures. The routine use of in- 
Anna Kircheva, Rumen Konstantinov

struction boards also acts as an alerting factor. Recent research points at the combined effect of various interrelated subsystems and socio-economic factors that are external for the institution. The developed practical model estimates the impact of two main subsystems:

1. Physical working environment - design, furnishing, technical equipment, lighting, temperature, ventilation, water, technical equipment, and communications.

2. Social working environment with components: individual characteristics - knowledge, experience, education, attitudes (motivation, attention, etc.); compliance with local practices; potential for furthering of one's classification; organization of the work process: provision of care for too many patients, teamwork, complexity of procedures, standardization, interference of competitive tasks, etc; management (hidden factors) - poor planning, indecisiveness, inaction (2).

The impacts introduced in the framework of a certain physical healthcare environment are subordinated to a comprehensive sociotechnical model. This model includes technical, ecological and social components, and an organization of microsystem management, as well as socio-economic factors that are external for the institution. The system starts with implementation of individual tasks related to patient healthcare and then expands to encompass factors from higher organizational levels. The system's proper functioning depends on the manner of interaction among all components $(33,34)$.

Human errors in healthcare often find their way into the mass media. Such errors are interpreted without mercy and the medic is disgraced before the society and the patients. The news of the error is linked to guilt, negligence, lack of attention, inexperience, etc. But it is important to understand that the error that has led to such irreversible unwanted result for the patient is an indicator for other system defects as well; the error is the tip of the iceberg that can guide us to the issues of the system. The assessment of every error must take into consideration the impact of a complex of factors. J. Reason created the Swiss Cheese Model. This model shows how a fault occurring in one layer of a system of care is usually not enough to cause an accident. Adverse events usually occur when a number of faults occur in a number of layers and momentarily line up to create the trajectory of an accident opportunity (34).

The involvement of the patients in the provision of safe healthcare is a very important practical approach. A good service needs to comply with the needs and perceptions of its recipients. In 2004, WHO engaged and promoted the initiative Patient for Patient Safety (PFPS). PFPS is a program of the World Health Organization which aims to create a global network of patient-leaders whose role is to support the initiatives for higher-quality healthcare $(35,36,37)$.

\section{CONCLUSION}

Unsafe medical care may cause substantial morbidity and mortality globally, despite imprecise estimates of the magnitude of the problem. To better understand the extent and nature of the problem of unsafe care, the WHO World Alliance for Patient Safety commissioned an overview of the international literature on patient safety research.

To better understand the causes and impact of the delivery of unsafe medical care from a global perspective, the World Health Organization (WHO) Patient Safety team convened an ad hoc expert working group to establish priorities for research on patient safety. To help set priorities, the group commissioned a report on the current evidence available. This assessment was done by identifying topics in patient safety, examining related clinical and organizational issues and distinguishing gaps in current knowledge and directions for future research.

The idea that health care actually harms patients has been around for some time, but until now little has been done to educate future doctors about the problem. Medical errors have high human and financial costs. However, the necessary knowledge for these cases might be imparted in any medical school curriculum. Comprehensive literature on the epidemiology and etiology of medical errors should be matched to related content in medical school curricula so that specific safety-related medical knowledge is developed. Incorporation of these recommendations can bolster the safety in academic medical centers by using medical students as a previously untapped advocate for patient safety. 
Patient Safety - Concept and Characteristics of Safety. The Human Factor Impact

\section{REFERENCES}

1. World Alliance for Patient Safety, Forward Programme, 2005.

2. WHO, $2012 \mathrm{http} / / \mathrm{www} . w h o . i n t / a b o u t / l i c e n s i n g /$ eu/index.

3. Jha AK, Larizgoitia I, Prasopa-Plaizier N, Waters $\mathrm{H}$, Bates DW. The global burden of unsafe medical care: analytic modelling of observational studies. BMJ Qual. Saf. 2013; 22: 809- 815.

4. Committee on the Quality of Health Care in America. Crossing the quality chasm: A new health system for the 21st century. Washington, DC: National Academy Press; 2001.

5. National Quality Forum. National consensus standards for nursing - sensitive care: an initial performance measure set. Washington, DC: National Quality Forum; 2004: 40.

6. Mitchell PH, Lang NM. Framing the problem of measuring and improving healthcare quality: has the Quality Health Outcomes Model been useful. Med. Care. 2004; 42: II4-11.

7. AHRQ PSNet, Patient Safety Network. Error chain. [Accessed October 20, 2007].

8. Huges RG, editor. Patient Safety and Quality, An Evidance-Based Handbook for Nurses. Agency for Healthcare Research and Quality; 2008.

9. WHO, Patient Safety, Report on the Burden of Endemic Health Care-Associated Infection Worldwide, 2011 http://www.who.int/gpsc/country_work/ burden_hcai/ru/.

10. World Bank list of economies. Washington, DC: The World Bank; 2009.

11. Brennau TA, Leape LL, Laird N, et al. Incidence of adverse events and negligence in hospitalized patients: results of the Harvard Medical Practice Study. New Engl. J. of Medicine. 1991;324 (6): 370 $-377$.

12. Wilson RM, Runciman WB, Gibberd RW, et al. The Quality in Australian Health Care Study. Medical J. of Australia. 1995; 163: 458 - 471.

13. Kohn LT, Corrigan JM, Donaldson MD, editors. To err is human: building a safer health system. A report of the Committee on Quality of Health Care in America, Institute of Medicine. Washington, DC: National Academy Press; 2000.

14. Arnaz-Andres JM, Aibar-Remon C, LimonRamirez R, et al. Prevalence of adverse events in the hospitals of five Latin American countries: re- sults of the Iberoamerican study of adverse events ( IBEAS ), BMJ Qual. Saf. 2011.

15. Clancy CM, Farquhar MB, Sharp BA. Patient safety in nursing practice. J. Nurs. Care, Qual., 2005; Jul.Sep.;20 (3): $193-7$.

16. National Quality Forum. Standardizing a patient safety taxonomy: a consensus report. Washington, DC: National Quality Forum; 2006.

17. Wandelt MA. Definitions of words germane to evaluation of health care. NLN Publ. 1976;(15-1611):57-8.

18. Lang $\mathrm{N}$. Issues in quality assurance in nursing. Paper presented at issues in evaluation research: an invitational conference; December 10-12, 1975; Kansas City, KS: American Nurses Association. 1976.

19. http://www.who.int/patientsafety/en/, 2013.

20. Report of the first meeting of the GCBS, WHO, Geneva, 14-17.11.2000. Available from: http.//www. who.int/bloodsafety/gcbs.

21. WHO, Fact Sheet №231 Injection safety: Misuse and overuse of injection worldwide. Available from: www.who.int/injection_safety/about/resources.

22. Beltrami EM, Williams JT, Shapiro CN, et al. Risk and management of blood-borne infections in health care workers. Clin. Microbiol. Rev. 2000; 13(3): 385 - 407.

23. Oldham J, Sinclair L, Hendry C. Right patient, right blood, right care: safe transfusion practice. $\mathrm{Br}$. J. Nurs. 2009; Mar. 12-25;18(5):312, 314, 316 - 20.

24. Guidance for Industry and FDA Staff - Medical Devices with Sharps Injury Prevention Features, FDA document; 2005 Aug.

25. Berry X, Voris V, White N, Salomone J, Diaz - Granados $\mathrm{C}$, et al. Reduction of Sharps Injuries in the Operating Room Following Implementation of a CDC - recommended Sharps Injury Prevention Program. SHEA's 17th Annual Scientific Meeting, Baltimore, MD. 2007 Apr:14 - 17.

26. Association for Professionals in Infection Control and Epidemiology (APIC). Available from: www. apic.org. Accessed December 3; 2004.

27. Community and Hospital Infection Control Association (CHICA)-Canada. Available from: http:// www.chica.org/association.html. Accessed December 3; 2004.

28. World Health Organization. The Global Patient Safety Challenge 2005-2006 Clean Care is Safer 
Care. World Health Organization, Geneva; 2005:

$1-25$.

29. WHO. Safe Surgery Saves Lives: the second global patient safety challenge. Available from: http://whqlibdoc.who.int/hq/2008/WHO_IER_ PSP_2008.07_eng.pdf,2008, accessed April 21, 2010.

30. Vincent C, Adams S, Stanhope N. A framework for the analysis of risk and safety in medicine. BMJ. 1998; 316: $1154-7$.

31. Carayon P, Smith M. Work organization and ergonomics. Appl. Ergon. 2000; 31(6): 649 - 61.

32. Vicente K. The human factor. New York: Routledge; 2004.

33. Cook R, Woods D. Operating at the sharp end: the complexity of human error. In: Bogner M, editor. Human error in medicine. Hillsdale, N.J.: Lawrence Erlbaum Associates, Inc; 1994: 255 - 310.

34. Schyve P. Systems thinking and patient safety. In: Henriksen K, Battles J, Marks E, Lewin, D., editors. Advances in patient safety: from research to implementation. Vol. 2, Rockville, MD: Agency for Healthcare Research and Quality; 2005: 1 - 4.

35. Longtin Y, Sax H, Leape LL, et al. Patient participation: current knowledge and applicability to patient safety. Mayo Clin. Proc. 2010; 85: 53 - 62.

36. Futge N, Wolfe CDA, Mc Kevitt C. Assessing the promise of user involvement in health service development: ethnographic study. BMJ. 2007, Online: doi: 10.1136 / bmj.39456.552257.BE.

37. Scott $\mathrm{T}$, Mannion R, Davies $\mathrm{H}$, Marshall M. The quantitative measurement of organizational culture in health care: a review of the available instruments. Health Services Research. 2003; 38:3; 923 -945 . 